\title{
EDITORIAL
}

\section{EL CURRÍCULO, UNA OPORTUNIDAD DE PARTI- CIPACIÓN EN LA CONSTRUCCIÓN PEDAGÓGICA}

La sociedad en que vivimos requiere pensar la educación, y en consecuencia la oferta académica para niños jóvenes y adultos. Ahora bien; ¿Qué concepciones de sujeto se plantean las instituciones educativas?, ¿Qué saber pedagógico orientan las propuestas curriculares de escuelas y universidades?, el currículo se piensa como una estrategia que organiza y da respuesta a las preguntas anteriores, además se fundamenta en conceptos de educación, pedagogía, didáctica, y por lo tanto la relación teoría-práctica y con ella la enseñanza y el aprendizaje; dichos conceptos han sido tomados desde distintas perspectivas teóricas y modos de ver la sociedad y la cultura a lo largo de la historia, sobretodo, como las estructuras políticas y sociales tejen diferentes relaciones que reflejan valores establecidos, tradiciones, perspectivas de trabajo y organización social.

Pedagogía y currículo, el tema central del número ocho de la revista Praxis $\&$ Saber, da la palabra a investigadores en el campo, encontrando relaciones problemáticas entre propuestas pedagógicas, políticas, sociales, culturales y la función de organizar, anticipar y guiar el sentido de la educación en las instituciones, una tarea dispendiosa y definitiva para nuestra sociedad. La experiencia en la vida académica e investigativa de algunos maestros demuestra la importancia de transformar y transformarse, la búsqueda permanente de oportunidades de participación en la construcción e innovación de propuestas pedagógicas, posturas críticas que van dejando de lado la idea de estructuras establecidas, objetivos por cumplir y programas por desarrollar de acuerdo con lo ordenado por las normas.

No es desconocido en el ámbito educativo colombiano que, así como las reformas y variaciones curriculares se pueden concebir como producto de una determinada orientación política y emblema hegemónico discursivo que determinan proyectos alrededor de: "calidad de la educación", "fortalecimiento de competencias profesionales", "gestión ágil", "igualdad 
de oportunidades", "autonomía institucional", temas de actualidad que pueden convertir al currículo en un lema para justificar la transformación educativa, por otra parte, el currículo puede ser visto como un espacio de interacción de docentes, estudiantes y comunidad educativa, en permanente transformación; manifestación de posturas pedagógicas, conflictos académicos, intereses específicos, debates políticos y en general una muestra de la vida en permanente movimiento que evidencia relaciones de poder.

Currículo, todo lo que los adultos quieren enseñar a los menores, criterios estatales verticales impuestos desde una unidad de sabiduría, la autoridad académica de las instituciones con la responsabilidad de preparar a los estudiantes para las pruebas académicas, o tal vez lo que cada profesor enseña, o lo que debe enseñar, o lo que cada docente enseña a su manera. Pensar el currículo es inevitable cuando se tiene la idea de generar una propuesta educativa, preguntarse sobre ¿Qué es lo que debe enseñarse?, ¿Cómo asumir las propuestas pedagógicas establecidas por el modelo pedagógico estatal?, ¿Cuál debe ser la pertinencia frente a las necesidades y vivencias de los estudiantes? Y como indicaría Díaz Barriga, el debate se encuentra entre la experiencia y la formalidad de la ciencia, por consiguiente, es necesario dar una mirada al proceso histórico que permite abordar y analizar la idea de currículo, entonces reportarse a los años 60 y 70, tiempo en que las reformas educativas en América Latina estaban direccionadas por los Ministerios de Educación que incorporan la pedagogía estadounidense en el marco de la Alianza para el progreso, con un enfoque técnico, y para su aplicación se reparten ejemplares distribuidos de manera gratuita.

En consecuencia, instituciones educativas y maestros atienden el llamado y se preparan para aplicar la propuesta, a partir de la teoría de Tyler que determina objetivos a seguir, sin embargo la experiencia de la escuela ya estaba planteada de alguna manera por maestros y estudiantes. Las instituciones fueron ajustándose a la estructura organizativa vigente, según lo dicta el tiempo, el autor y en consecuencia la teoría, mientras las experiencias ya existentes como realidades exigen un análisis social y cultural, no simplemente para ser explicado por las teorías sino para cuestionar y construir en conjunto con ella.

Escribir sobre pedagogía y currículo implica contar con dichas manifestaciones de poder de un currículo oficial que se establece, pero a su vez genera interrogantes sobre el ser el poder y el conocer: ¿Qué es el currículo?, ¿Cuál es la relación entre discursos, prácticas y políticas públicas?, ¿Qué procesos de reflexión e innovación se plantean en este campo?, ¿Qué 
papel han desempeñado los educadores?, ¿Qué posiciones epistemológicas, metodológicas y teóricas emergen? ¿Cómo las prácticas pedagógicas dan lugar a maneras de concebir el currículo? referirse al ser, poder y conocer en la educación implica referirse a la vida misma, siguiendo a Da Silva, el currículo invita a ser visto como nuestro espacio, nuestro territorio por el que hacemos un recorrido y transcurre nuestra vida.

En suma, esta reflexión propicia un movimiento conceptual necesario en las instituciones educativas para pensarse en su quehacer desde múltiples maneras. Esta oportunidad de hablar sobre el currículo propicia encuentros, nuevos significados y maneras de decir, de escribir sobre lo que se investiga es, como diría Skliar, darse a sí mismo a través de los signos, una responsabilidad de pensar para otros, ¿cómo decir a otros sobre la vida? sobre la escuela?, sucede entonces un intercambio, un juego de diferencias que mediante la escritura va dejando huella.

Poner en cuestión la estructura que tenemos puede ser el reto, los autores presentes en esta edición favorecerán los cuestionamientos, la búsqueda, pero también las oportunidades que tenemos de transformarnos para dar nuevas respuestas a viejas preguntas: ¿Qué es lo que debe ser enseñado?, o ¿Qué es lo que debe ser construido?, ¿Dónde queda el "ideal” de ser humano formado para un determinado tipo de sociedad?

Las palabras puestas en cada uno de los artículos, invitan a ser reinterpretadas, reevaluadas, para dar vida al discurso de la pedagogía y el currículo y por tanto a la escuela, esa escuela que se encuentra refundida, enmarañada en el tiempo y el espacio diseñada por viejos esquemas curriculares que aprisionan a maestros y estudiantes y dejan que la verdadera vida en su total complejidad discurra en otros lugares, donde el permanente movimiento da lugar para que circule.

Este número recoge aportes de docentes de universidades como: Universidad Politécnica Salesiana, Quito, Ecuador, Universidad Pedagógica Nacional, Bogotá, Colombia, Universidad Tecnológica de Pereira, Colombia, Fundación Universitaria Monserrate, Bogotá Colombia, Universidad Industrial de Santander, Colombia, Universidad de Granada, España, Universidad Santo Tomás, Universidad Nacional de Colombia sede Caribe, Universidad Nacional Abierta y a Distancia, Fundación Universitaria Unipanamericana, Universidad Virtual Tecnológico de Monterrey de México, Universidad de Bologna, Italia Mescud, CADE, Universidad Distrital Francisco José 
de Caldas, Bogotá, Colombia y Universidad Pedagógica y Tecnológica de Colombia. Se incluyen artículos de investigación y artículos de reflexión como resultado de investigación.

"Relaciones conflictivas: pedagogías críticas y currículum" es el título del artículo con el que María Verónica Di Villoslada desarrolla un análisis sobre los aportes de las pedagogías críticas a la educación y sus dificultades e incongruencias para generar transformaciones importantes a nivel curricular, considerando la concepción de sujeto y sociedad como el punto de convergencia de la problemática educativa que encuentra allí una posibilidad de superación.

El proceso reflexivo sobre los estilos pedagógicos que reflejan las prácticas y procesos de innovación curricular de profesores universitarios, constituye el objeto central de análisis del artículo de María Mercedes Callejas R., Leonor Gómez Gómez, Marta Cecilia Gutiérrez y Alberto Pardo Novoa. "La reflexión sobre los estilos pedagógicos y la innovación curricular en la universidad". La conformación de comunidades académicas a través de la investigación, permitirá tomar conciencia de la concepción de currículo y la de formación del ser humano.

Álvaro Acevedo Tarazona en su artículo "Huellas, resonancias y lecciones del movimiento pedagógico en Colombia" valora las luchas de los educadores colombianos y propone una reflexión de la educación y los educadores en relación con el mundo contemporáneo, el despliegue del capitalismo que domina las naciones Latinoamericanas.

En el artículo "Matricular las emociones en la escuela, una necesidad educativa y social", Rafael Buitrago Bonilla y Lucía Herrera Torres, analizan el papel de las emociones en la escuela, poniendo en evidencia que no es posible separar la emoción de la cognición, por lo tanto la importancia del desarrollo de habilidades emocionales debe pensarse de la misma manera que se piensa el desarrollo de cualquier disciplina fundamental en la escuela, aquellas, especialmente como fortalecimiento de la interioridad de los individuos.

Julio Fernando Acosta Muñoz con su artículo "Las actitudes investigativas en la formación escolar" reflexiona sobre las dificultades en la formación de jóvenes en investigación, la influencia de los paradigmas de la ciencia, los modelos, las prácticas dogmáticas como formas de mantener el control y conocimiento de la verdad, versus actitud investigativa como experiencia, 
capacidad de asombro, forma de autoconocimiento, de ser y estar en el mundo.

En el artículo "Estudios de lo imaginario: orígenes y trayectos", Patricia Pérez Morales analiza la importancia de comprender los fenómenos sobre lo imaginario y lo simbólico planteando lecturas contextuales que permiten concebir el conocimiento desde un acercamiento entre el sentido común y la ciencia, haciendo evidente que hay formas que no encajan dentro de los modelos preestablecidos.

La reflexión central sobre el proceso formativo de docentes desde las prácticas pedagógicas, identificando aprendizajes, transformaciones y tensiones, presentada en el artículo "Análisis crítico de la práctica pedagógica de docentes en formación” presentada por Mónica Ruiz Quiroga, Cristian Camilo Ortiz Castiblanco y Jhider Soler Mejía da cuenta de concepciones y representaciones de los estudiantes acerca de la formación investigativa, pedagógica y disciplinar.

"Una mirada al programa ONDAS en San Andrés Isla: aportes pedagógicos y sociales" es el título del artículo presentado por Paula Andrea DuarteTorres, Jenifer C. Hernández Vásquez y Jairo Humberto Medina en el que muestran la participación de docentes y estudiantes en el proyecto ONDAS, el impacto socio-educativo desde la investigación, generando expectativas de vida, cooperación, participación en procesos educativos por parte de estudiantes y maestros, con alta motivación hacia el cambio y el progreso.

Yenny Tatiana Avellaneda Avellaneda presenta como tema central, una relación entre escuela-infancia-política. La función de la escuela frente a la vulneración de derechos, en el artículo "Formación política en y desde la escuela. Aportes para construir la relación infancia-escuela-política". Las situaciones adversas, conflictivas, de abandono, indiferencia, negación $\mathrm{y}$ violencia que viven niños y niñas; la acción reducida de la escuela desconociendo la situación social.

El interés por el habitual sujeto de la cultura y el sujeto de carácter virtual y la necesidad de prácticas tecno-pedagógicas propias de ambientes virtuales de aprendizaje, es el tema central del artículo "Sujeto y producción textual en el campus virtual” dónde Diana Mireya Cuéllar Sánchez y Alfonso Alberto Angarita Buitrago pretenden generar un espacio de discusión respecto al ejercicio virtual en el proceso educativo. 
En el artículo "Método <traducción gramatical>, un histórico error lingüístico de perspectiva: orígenes, dinámicas e inconsistencias" Camilo Andrés Bonilla Carvajal analiza la gramática-traducción como una etiqueta histórica arbitraria en la historia de la enseñanza del idioma, el modelo negativo de la práctica docente que debe ser evitado.

Luz Myrian Muñoz Sierra, en el artículo "Powerpoint y el Desarrollo del pensamiento lateral del estudiante" expone las ventajas del uso del programa PowerPoint para el desarrollo del pensamiento lateral en estudiantes, generando creatividad, flexibilidad, fluidez, originalidad, además de reflexión como parte del pensamiento crítico, este último facilita el conocimiento ordenado de la realidad.

Finalmente “Sobre algunas 'D' en didáctica de la matemática: designación, denotación, denominación, definición, demostración. Reflexiones matemáticas y didácticas que pueden conducir lejos" es el título del artículo con el que Bruno D’Amore y Martha Isabel Fandiño Pinilla, desarrollan la importancia de las operaciones de designación, denotación (y cognotación), denominación, descripción, definición y de demostración, momentos matemáticos útiles en la formación inicial de los docentes de matemática.

Por lo anterior, es claro reconocer la multiplicidad de saberes en pedagogía y en currículo, maneras distintas de comprender y construir conocimiento que evidencian además la amplitud de las problemáticas, indica esto que el conocimiento no es acumulativo sino diferente. Nos enfrentamos a nuevos retos, la multiplicidad y el valor de la diferencia en un campo de acción complejo. Pensar la pedagogía y el currículo desde el sujeto que aprende y se transforma permanentemente en un contexto en movimiento, necesita ser valorado no solamente desde las normas impuestas por una estructura homogenizante.

Praxis \& Saber presenta un espacio de discusión para quienes participan en la línea Pedagogía y Currículo de la Maestría en Educación y los círculos académicos asociados, un espacio para exponerse y generar interés en el lector, que desde ya es considerado un participante, un acompañante a pensar el currículo y la vida en la escuela. 